\title{
The art of second wave positive psychology: Harnessing Zen aesthetics to explore the dialectics of flourishing
}

\author{
Tim Lomas
}

\begin{abstract}
In recent years, a "second wave" of positive psychology has been emerging, characterised, above all, by an awareness and appreciation of the dialectical nature of flourishing. This paper offers a philosophical foundation for this second wave, based on Eastern philosophy, and, in particular, Zen aesthetics. Part one introduces Zen, including its key philosophical ideas and practices, as well as two antecedent traditions that helped to form it, namely, Buddhism and Taoism. Part two then elucidates three aesthetic principles that are integral to Zen: mono no aware (pathos of life), wabi-sabi (desolate beauty), and yügen (profound grace). The paper discusses how these principles could be of value to positive psychology in fostering dialectical understanding and appreciation, thus highlighting future directions for the field.
\end{abstract}

Keywords: aesthetics, philosophy, Zen; flourishing, dialectics

\section{Introduction}

Positive psychology (PP) initially defined itself by a focus on "positive" aspects of human functioning (Linley \& Joseph, 2004). This focus carried the implicit (and often explicit) message that positive phenomena were inherently desirable, and should be sought, and conversely that "negative" aspects of life were intrinsically undesirable, and should be eschewed. However, critical theorists from inside (e.g., Wong, 2011) and outside (e.g., Held, 2004) the field have highlighted flaws in this message. For instance, McNulty and Fincham (2011) argued that the value of any given phenomenon inextricably depends upon the dynamics of context. Ostensibly positive qualities can be detrimental in certain situations; for instance, "excessive optimism" is linked to health risk behaviours (Norem \& Cantor, 1986). Conversely, seemingly negative qualities can be conducive to flourishing if harnessed skilfully; as Seligman (1990, p. 292) put it, one must be "able to use pessimism's keen sense of reality when we need it." Such observations call into question the validity of categorically classifying phenomena as either positive or negative. Indeed, there is much critical debate within the field generally around the very notion of the "positive," as exemplified by the recent articles by James Pawelski (2016a, 2016b). For instance, Lazarus (2003) pointed out that many emotional states are actually "co-valenced," involving a complex blend of light and dark elements. A classic example is love, which is, as Bauman (2013, p. 6) puts it, "that most sublime of all human conditions, one in which fear blends with joy into an alloy that no longer allows its ingredients to separate."

However, although these critical observations have challenged PP, they have not undermined it. Rather, we have seen the emergence of what Held (2004) calls a "second wave" within the field, which Wong (2011) refers to as PP "2.0." This second wave still focuses on the same fundamental meta-concepts around which the field initially crystallised, from wellbeing to 
flourishing. However, it does so in ways that embrace the critical points raised above, developing a more nuanced understanding of the complex dynamics of so-called positive and negative aspects of experience (see Lomas \& Ivtzan, 2015; Ivtzan, Lomas, Hefferon, \& Worth, 2015). Summarising this second wave approach, Wong suggests it is characterised by a deep appreciation of the dialectical nature of flourishing. Although "dialectics" encompasses a range of meanings, it essentially refers to the dynamic "tension of opposition between two interacting forces or elements" (Merriam-Webster, 2014). For instance, dialectics can refer to the way in which conceptual opposites, although diametrically opposed, are also intimately connected and co-creating; e.g., "good" can only be recognised by counterposing it with "bad." Thus, second wave PP recognises that flourishing involves "inevitable dialectics between positive and negative aspects of living" (Ryff \& Singer, 2003, p. 272). This includes a creative and generative tension between polarities like freedom and restriction (Schwartz, 2000), optimism and pessimism (Norem \& Cantor, 1986), anger and forgiveness (McNulty \& Fincham, 2011), boredom and curiosity/creativity (Lomas, 2016a), and even happiness and sadness (Ahmed, 2010).

So, second wave PP recognises that the good life does not involve being a "well-defended fortress, invulnerable to the vicissitudes of life," as King (2001, pp. 53-54) puts it, but, rather, appreciating and even embracing the complex and ambivalent nature of life. Given this, one of the key tasks facing PP is to explore ideas and practices that might help us - PP as a field, and, indeed, people generally - to cultivate this kind of appreciation. To this end, this paper proffers one potential resource that might facilitate this, namely, aesthetics - a branch of philosophy concerning the nature and forms of beauty (Brady, 2013). Efforts are already underway within $\mathrm{PP}$ to recognise the role of the arts in promoting flourishing, as seen in Lomas' (2016b) notion of "positive art." However, in terms of developing an appreciation of dialectics specifically, there may be much to be gained from exploring the aesthetic principles propounded by Eastern philosophy in particular. (Indeed, this approach aligns with attempts more broadly within PP to engage with and learn from non-Western cultures; see e.g., Lomas, 2015; Lomas 2016d.) Whilst Eastern philosophy encompasses a multitude of traditions, these share a deep understanding of dialectics, as does Eastern culture generally (Schimmack, Oishi, \& Diener, 2002). Moreover, these traditions have embraced art and aesthetics as a vehicle for expressing their spiritual insights, and thus also aesthetic appreciation as a potent means of cultivating such insights.

This pivotal role of art and aesthetics is encapsulated in one of the archetypal symbols of the East, the yin-yang motif associated with Taoism. This is the ultimate dialectical symbol, capturing in stark, beautiful simplicity the way that opposites - light and dark, positive and negative - exist within a dynamic "mutually constituting relationship" (Sameroff, 2010, p. 9). Taoism, and Buddhism more generally, both have an appreciation of dialectics at their core, and, moreover, have both used art and aesthetics to convey their spiritual insights in this regard, as discussed further below (in part one). However, it is arguably in Zen where the engagement with dialectics through art/aesthetics truly comes to fruition. As such, this paper will focus on the aesthetic philosophy of Zen in particular. The paper is in two parts. Part one introduces Zen, including some of its key philosophical ideas. Part two then focuses on its aesthetic principles, examining how these could be used within PP to foster an appreciation of dialectics.

\section{Zen}

This first part briefly introduces Zen, thereby preparing the groundwork for the discussion of its aesthetic principles in part two. Zen was the intermingled product of numerous Eastern traditions, particularly the confluence of Buddhism and Taoism. It is beyond the scope of this paper to give anything more than a cursory introduction to these immense traditions. 
Nevertheless, our appreciation of Zen will be enhanced if we can gain some sense of the tributaries that combined to create this particular stream of thought and practice. Thus, I shall touch briefly upon Buddhism and Taoism, before finishing by introducing Zen itself.

\subsection{Buddhism}

I shall begin here by discussing Buddhism. A more detailed account would preface this by exploring the way Buddhism itself grew directly out of Brahmanism - the multitude of religious beliefs and practices in the Indian subcontinent, stretching back into unrecorded antiquity, that today are labelled as "Hinduism" (King, 1999) - much as Christianity emerged out of Judaism. However, it shall suffice to note here that Gautama Siddhartha, better known by the honorific "Buddha" ("Enlightened one"), lived and taught in a cultural context - circa 480-400 BCE, or possibly even earlier (Coningham et al., 2013), in present-day Nepal - that was entirely suffused with Brahmanism. However, so significant and innovative was his experience and interpretation of the Brahmanical dharma ("laws" or "teachings") that his subsequent followers endowed his teachings with the status of a new religious tradition (Gombrich, 2006).

While there are many complex nuances to the Buddha's adaptation of Vedanta (the key Brahmanical texts), Gombrich (2006) suggests that one point stands out: whereas the Vedanta is fundamentally essentialist, the Buddha promulgated a form of anti-essentialism. He taught that existence is characterised by three lakshanas ("marks of conditioned existence"): anicca (impermanence), anattā (insubstantiality), and dukkha (dissatisfaction/suffering). He argued for the inherent "emptiness" of existence (Burton, 2001); not in the nihilistic sense that nothing is real, but, rather, that all phenomena are empty of a fixed, enduring, independent nature, but instead are transitory (anicca) and interdependent (anattā). These observations also apply to persons themselves, therefore, in contrast to the essentialist Vedic notion of the atman, the Buddha spoke of anatman (i.e., no self). However, he did agree with the Vedas that it is people's tendency to deny or ignore these fundamental ontological truths, and the related attempt to attach to phenomena that are inherently changeable, that ultimately causes much of human beings' suffering/dissatisfaction (dukkha). Moreover, the Buddha agreed with Brahmanism that liberation from suffering was possible. However, having disavowed the Vedanta notion of atman - some inner essence that would be the vehicle for or recipient of liberation - he suggested that enlightenment would come through seeing all forms of selfhood as an illusion, leading to the ultimate and supreme state of nirvana.

Leaving aside esoteric intricacies, the incontestable message of the Buddha is the possibility of liberation from suffering. Central to this message were the Four Noble Truths, a remedy for alleviating suffering: suffering is universal; it has a cause; cessation is possible; it can be achieved by following "the Noble Eightfold Path." This path essentially constitutes prescriptions for "right living," comprising wisdom (right vision and conception), ethical conduct (right speech, conduct, and livelihood), and meditation (right effort, mindfulness, and concentration) (Thrangu, 1993). Furthermore, at the heart of the Buddha's teachings was a deep appreciation of dialectics, which would subsequently feature prominently in adaptations such as Zen. This appreciation is reflected in the foundational idea of the "Middle Way," the phrase the Buddha often used to describe the Noble Eightfold Path. For instance, in his foundational Dhammacakkappavattana sutta, the Buddha characterised this middle way as a "golden mean" - cf. Aristotle (Cunningham, 1999) - between punitive asceticism and sensual indulgence.

As with most religions, following the Buddha's death, various schisms occurred, separating off into different schools. The early Therevadan traditions adhered closely to the Tipitaka (the Pali canon comprising the earliest surviving record of the Buddha's teachings, like the Noble 
Eightfold Path (Lomas, 2016c)). In subsequent centuries, schools emerged which developed these original teachings in innovative ways - including the pivotal dialectical idea of the Middle Way - with these schools often referred to collectively as Mahayana (Williams, 2008). It is from this latter group that Zen emerged, as we shall see shortly. Finally, Vajrayana refers to a further efflorescence of philosophical and ritualistic development that occurred from the $3^{\text {rd }}$ century CE onwards, particularly in Tibet (Davidson, 2003). Of particular relevance to the present paper is the fact that many of these varied schools of thought began to harness the power of art and aesthetics in expressing and communicating their spiritual teachings and insights. For instance, besides the centrality of art and aesthetics to Zen, another prominent example of the use of art in Buddhism is the creation of intricate mandalas - geometric, symbolic patterns imbued with deep meaning, fashioned using coloured sand - in Tibetan Buddhism (Bryant, 2003). We shall, of course, explore the role of art/aesthetics in Zen in depth below. However, before we turn our attention to Zen, we need a second piece of the puzzle: Taoism.

\subsection{Taoism}

Taoism is an overarching philosophy and way of life that is indigenous to China. Like Buddhism, it is thoroughly imbued with an understanding and appreciation of dialectics. It centres on the nebulous idea of "the Tao," which Oldstone-Moore (2003, p. 6) describes as a "nameless, formless, all pervasive power which brings all things into being and reverts them back into nonbeing in an eternal cycle." Although its origins lie in unrecorded antiquity, its formative influence is the I Ching, or "Book of Changes." The I Ching initially began life over 3,000 years ago as a shamanic practice among the Chou people; it then crystallised in written form around the time of King Wen (circa 1150 BCE) and his son, although the iteration that has reached us today is the version edited and annotated by Confucius around the $5^{\text {th }}$ century BCE (Wilhelm, 1950). The I Ching emerged from the practice of consulting oracles: initially, binary yes/no oracles were used (e.g., cracks in tortoise shells), with "yes" represented by an unbroken line, and "no" by a broken line. To allow for further differentiation, lines were later combined in pairs, and then triads; finally these "trigrams" were themselves paired up, creating 64 hexagrams (i.e., permutations of broken and unbroken lines). Divination practices typically involved asking a question, then throwing yarrow stalks upon the ground, with the resulting arrangement being interpreted as a particular hexagram. The I Ching thus emerged as a guide to assist in the interpretation of these hexagrams. However, the key point - in terms of the dialectical philosophy at the heart of Taoism - is this: the hexagrams represent not states of being, but of becoming. The focal point of the hexagrams is always the "moving" lines, i.e., any of the six lines that are dynamic or "unstable," which would thus herald the shift to a different hexagram.

As such, the overarching philosophical principle of the I Ching is change, which, paradoxically, is the one stable and consistent law at work in the universe. As Wilhelm (1950) puts it, "He who has perceived the meaning of change fixes his attention no longer on transitory individual things but on the eternal, immutable law at work in all change," and it is here, in the I Ching, that we find the origin of Taoism, for this immutable law is "the Tao, the course of things, the principle of the one in the many." Moreover, the I Ching did not only recognise the fundamental ubiquity of change, it also identified the mechanism through which it occurs: the dialectical interaction between opposites (Fang, 2012). Thus, as per Buddhism (with its notion of the Middle Way), Taoism has an appreciation of dialectics at its core. Indeed, this dialectical philosophy was subsequently captured symbolically by the yin-yang motif, which, above all else, has come to symbolise Taoism (though the terms themselves do not appear in the IChing; instead we find dichotomies such as "the firm" and "the yielding"). 
"Yin" means cloudy/overcast, whereas "yang" means "in the sun" (i.e., shone upon), implying the two sides of a mountain (one sunlit, one in shadow) (Lomas, 2016d). Thus, as Fang (2012) explains, yin-yang encapsulates various "tenets of duality." The tenet of "holistic duality" means that reality comprises co-dependent opposites that each require the other for their existence (e.g., "up" depends upon the notion of "down"). Moreover, the tenet of "dynamic duality" holds that these opposites tend to mutually transform into each other in a dynamic process; as Fung (1948, p. 19) puts it, "When the sun has reached its meridian, it declines" (i.e., its zenith heralds the beginning of the descent into night). Thus, yin-yang does not simply present a pair of static opposites, but includes an element of darkness in the light, and vice versa, capturing the ceaseless process of becoming. As Ji, Nisbett, and Su (2001, p. 450) put it, "The pure yin is hidden in yang, and the pure yang is hidden in yin." As a final point on this notion of yin-yang, it is particularly noteworthy - from the perspective of the present paper - that it should be so indelibly associated with an artistic image. This again reinforces the central point of this paper, namely, the unique power of art to communicate spiritual insights, and thus also the role of aesthetic appreciation as a means of understanding such insights.

Indeed, the overarching message of Taoism is that a deep experiential understanding of the dialectics of the Tao - as reflected in the yin-yang motif - is the path to liberation. The scriptural basis for Taoism itself is the Tao Te Ching, attributed to a sage/mystic named Lao Tzu, who possibly lived at some point between the sixth and third centuries BCE (Barnett, 1986). (His existence is disputed, since no historical records of him exist, and "Lao Tzu" means "old master," so the book may "just" constitute a compendium of Taoist folk wisdom.) The Tao Te Ching is not simply a philosophical explication of the Tao, and of principles such as yin-yang. As with the Vedas and the Buddha's teachings, it offers a path of liberation from suffering. In particular, it suggests that suffering arises from ignorance of the Tao, and from resisting the dynamic flux of life. As Smith (1972, p. 77) puts it, "Human beings, by turning away from the Tao, bring suffering and chaos into their affairs." Conversely, liberation may be found through living in harmony with the natural operations of the Tao. As expressed in Verse 47, "Mastery of the world is achieved by letting things take their natural course."

Moreover, Taoism held that this ability to live in harmonic accord with the Tao - represented by the Chinese term te - can be cultivated through psychospiritual meditative practices (Kirkland, 2004), such as tso wang ("sitting with a blank mind") or hsin tsung (finding the still place in the centre of consciousness). Thus, Taoism upheld the possibility of becoming subjectively "one" with the Tao. However, in contrast to the more abstract and esoteric speculations of Brahmanism (and some schools within Buddhism), the Taoist path to liberation was more "down-to-earth," consisting more of not resisting the way of nature (Hermann, 1990). Taoism upheld the virtue of $w u-w e i$ - as articulated by the great Chuang Tzu (circa $3^{\text {rd }}$ century BCE) - which translates as "non-action," but which really means surrendering to and aligning oneself with the Tao, and allowing one's actions to be as "spontaneous and free-flowing as the natural world." As Chuang Tzu said, "The perfect man has no self; the spiritual man has no achievement; the true sage has no name" (cited in Ho, 1995, p. 120). And it was when Buddhism travelled to China and encountered Taoism, that we find the birth of Zen.

\subsection{Zen}

Essentially, when Buddhism was transmitted to China, it mingled with Taoism to produce Zen. As the great Buddhist scholar D. T. Suzuki (1961) put it, "Zen is the product of the Chinese soil from the Indian seed." This transmission is often attributed to the arrival in China of the Indian Buddhist monk Bodhidharma, in $520 \mathrm{CE}$, who subsequently became known as the "first 
patriarch" of Zen (Watts, 1957). However, Watts argues that "the appearance of trends very close to Zen" are evident almost as soon as Mahayana sutras became available in China, which occurred at least as early as $384 \mathrm{CE}$ through translations by the Indian scholar-monk Kumarajiva (p. 100). As Buddhism entered China, we see a fascinating process of adaptation, with the teachings and practices assuming new forms to align with local culture - above all, Taoism. Key features of Buddhism were, of course, retained, not least the possibility of enlightenment, and the value of meditation as a means towards "attaining" this. Indeed, Zen itself means "meditation," or, more accurately, Zen is a Japanese rendering of $C^{\prime}$ 'an, which was the Chinese term for the Indian word dhyana, which means "meditation." We should note, though, that Taoism already had its own forms of meditation, so this is not simply an Indian practice "exported" into China (Kirkland, 2004).

However, Buddhism in China began to take on a very different form, influenced above all by the Taoist tradition that dominated in China (alongside Confucianism). In the Indian subcontinent, Buddhism had been strongly shaped by the Brahmanic context in which it emerged, as noted above. For instance, Brahmanism included elements of polytheism, and tendencies towards abstract metaphysical analyses (King, 1999). These types of features thus often suffused Mahayana Buddhism, leading to a proliferation of mythological and esoteric schemas. This type of abstract philosophising jarred with the practical, "down-to-earth" nature of Taoism. Consequently, Chinese Buddhists began dispensing with what they regarded as unnecessary and unhelpful mythological speculations. Instead, Buddhism in China - which, for convenience, I shall just refer to as "Zen" - sought to explain and interpret the Buddha's message of liberation using ideas from Taoism. This Taoist spirit was maintained, and, indeed, developed further, when Zen was introduced into Japan in 1191 by the Japanese monk Eisai (1141-1215), who founded the Rinzai school (based on the teachings of the $9^{\text {th }}$ Century Lin Chi), and later by Dogen (1200-1253), who founded the Soto school.

For instance, from the Taoist principle of wu-wei, Zen Buddhists derived the idea that enlightenment did not necessarily have to involve an arduous sequence of mental training, leading to a gradual ascent to this summit of spiritual development. Rather, Zen suggests that "all" that is needed to attain enlightenment is for one to act naturally and spontaneously in accordance with the Tao. This suggestion is evident in one of the first clear statements of Zen, attributed to Seng-ts'an (circa 600 CE), in his poem Hsin-hsin Ming (Treatise on Faith in the Mind), which states, "Follow your nature and accord with the Tao; Saunter along and stop worrying... Don't be antagonistic to the world of the senses, For when you are not antagonistic to it, It turns out to be the same as complete awakening" (cited in Watts, 1957, p. 109). This notion that liberation consists in following one's nature is reflected in the famous definition of Zen given by Po-Chang (720-814 CE), "When hungry, eat; when tired, sleep." Indeed, the person realises that since they too are an expression of the Tao, there is no way they cannot act in accordance with it. Thus, there is no need to strive towards Buddhahood (i.e., "attaining" enlightenment); rather, the task is to recognise that one already has a "Buddha nature" (is already enlightened). Consequently, Zen places great emphasis on the possibility of "sudden" awakening: an immediate realisation in which one sees through the illusory construct that is one's ego, and grasps in its completeness one's Buddha nature.

Of course, although recognising one's Buddha nature is ostensibly presented in Zen as a simple act, in reality it is anything but. For this reason, Zen developed various practices aimed at provoking this kind of awakening. For instance, Zen places great emphasis on za-zen (meditation), particularly within monastic settings (Watts, 1957). There was also the extraordinary development of the koan system, designed to test practitioners' spiritual insight. 
These were "riddles" that could not be solved with the conventional intellect - e.g., "What is the sound of one hand clapping?" - thereby creating a cognitive impasse, characterised by "great doubt" (Suzuki, 1961); the trainee would thus dwell upon these imponderables, until the impasse suddenly gave way to a breakthrough of insight. And then there is art, which Zen found to be a particularly effective vehicle for communicating and inculcating its ideas, as the next part explores.

\section{Zen aesthetics}

Having now briefly introduced Zen, this part now explores its aesthetics. There are many ways in which this topic could be approached, and, indeed, numerous reasons for doing so. As such, it is worth restating the purpose of this paper: to find an aesthetic mode that may allow us to appreciate the dialectical nature of life, and consequently to provide an aesthetic basis for second wave PP. Thus, it is not the aim here to explicitly demonstrate that the practice and appreciation of Zen can be the basis for spiritual liberation - although this may well, indeed, be the case - or to promote Buddhism. Rather, the more modest aim is simply to elucidate some Zen aesthetic principles that can illuminate the kind of dialectical insights being explored in second wave PP. Indeed, Wong's (2011) exposition of this second wave - PP 2.0, in his terminology - was based on his knowledge and understanding of Zen dialectical principles. Readers interested in the influence of Zen on PP 2.0 are thus further encouraged to read Wong's (2009a, 2016a) work on "Chinese Positive Psychology."

Firstly though, let's say a little about the importance of aesthetics within Zen. In Zen, art is seen as a particularly potent way of communicating spiritual truths, indeed, far more so than discursive prose. Zen constantly seeks to eschew and overcome the limitations of conceptual thought, and to "point directly" into the "suchness" (i.e., nature) of reality. As Chung-yuan (1977, p. xvii) puts it: "Chinese aesthetics is not a rational system of thought, but a direct, intuitive experience, which contains within it certain basic, profound and subtle meanings essential to the attainment of the One." And art is uniquely effective at just this kind of pointing, indeed, Hermann (1990) describes art as the highest (though still inadequate) vehicle for truth. In Zen, artistic creations enable adepts to reveal and express their spiritual insights, highlighting their "direct seeing" into the nature of reality. Moreover, simply learning to appreciate Zen aesthetics (i.e., without necessarily practising oneself) can also be a potent route to spiritual illumination. As such, Bai (2002, p. 12) reports that Zen "pervaded the arts and crafts, indeed all aspects of everyday life" in medieval China and Japan - from flower arrangement to swordsmanship, poetry to painting - and rendered them vital expressions of and ways towards spiritual experience. This helped to universalise and democratise Zen, bringing it out from the monastery and into people's daily lives.

Zen aesthetics is abundantly blessed with a multitude of concepts and practices that are, unfortunately, beyond the scope of this paper. For instance, innumerable works have been devoted to Zen artistic traditions, and to the qualities embodied in them. One might mention the tea ceremony, for example, as elucidated by the Tea Master Takuan Soho (1573-1645). Interpreting his work, Hammitzsch (1979) suggests it comprises four key concepts. Kei (reverence) refers to mutual deference and respect from the participants, and concomitant control of the ego. Wa (harmony) reflects the experience of nonduality, in which the self does not stand apart from the other, but participates in a union of "interbeing" (Nhat Hanh, 2000). Sei (purity) signifies that the "heart-mind" is free from the turbulent emotions which usually tend to disturb its equanimity. Finally, jaku (tranquillity) refers to the nature of the resulting untroubled mind. Such analyses abound in Zen, depicting the significance of art forms ranging from archery to 
poetry (Suzuki, 1961). However, of most relevance in the context of this paper are Zen principles of aesthetic appreciation. These can help us to discern and even find subtle beauty in the mysterious, dialectical nature of existence, and thus may serve as an aesthetic basis for second wave PP. I shall explore three key principles in particular: mono no aware (the pathos of life), wabi-sabi (desolate beauty), and yūgen (profound grace). There are other potentially relevant principles, such as the seven identified by Hisamatsu (1971): fukinsei (asymmetry), kanso (simplicity), koko (austere sublimity), shizen (naturalness), daisuzoku (freedom from attachment), sei-jaku (tranquillity), and yügen. However, according to Watts (1957), mono no aware, wabi-sabi, and $y \bar{u} g e n$ are the three main perceptual-emotional "moods" that Zen aims to evoke, and so are perhaps the most apt for demonstrating the relevance of Zen aesthetics to second wave PP. These will be addressed in turn. In doing so, the paper will mainly draw on Japanese literature. However, further to the notion of "Chinese Positive Psychology" (Wong, 2009a; Wong, 2016a), alluded to above, it is worth emphasising that these aesthetic principles were also explored with great depth and subtlety in Chinese art, such as the flowering of poetry during the Tang (618-907 CE) and Song (960-1279 CE) dynasties.

\subsection{Mono no aware}

Mono no aware encapsulates the pathos (evocation of compassion or sorrow) derived from awareness of the fleeting, impermanent nature of life. The term was coined by the $18^{\text {th }}$ century literary scholar Motoori Norinaga - by combining aware, meaning "sensitivity" or "sadness," and mono, meaning "things" - to reflect what he saw as being a dominant Japanese aesthetic sensibility over the preceding centuries. This is captured, for example, in the opening of the epic $14^{\text {th }}$ century Japanese folktale, The Tale of the Heike: "The sound of the Gion shoja bells echoes the impermanence of all things ... The proud do not endure, they are like a dream on a spring night." As outlined above, recognition of the impermanence and transience of life is a central tenet of most Eastern philosophies, e.g., in Buddhism, anicca (impermanence) and anattā (insubstantiality) are two of the three lakshanas ("marks of conditioned existence"). The importance of this recognition is that denial or ignorance of anicca and anattā, clinging resolutely to phenomena that are intrinsically subject to change, is seen as an ultimate cause of the third lakshana, dukkha (dissatisfaction/suffering). Conversely, then, liberation can be found through a deep understanding and acceptance of anicca and anattā.

With mono no aware, though, this acceptance is elevated into an aesthetic sensibility that to an extent can even appreciate this ephemerality, embracing the fragility and finitude of life (Wong, 2012). This does not mean impermanence is welcomed or celebrated. There is still sadness present, a pathos at this transiency. However, mono no aware is a complex, refined emotional state in which this sadness is combined with a quiet rejoicing in the fact that one had the chance to witness the beauty of life at all, however fleetingly, and recognition that its ephemerality was somehow integral to its very beauty. As expressed by Yoshida Kenkō (1283-1350), "If man were never to fade away like the dews of Adashino ... how things would lose their power to move us! The most precious thing in life is its uncertainty" (cited in Keene, 1967, p. 7). In Zen, the preeminent symbol of mono no aware is the cherry blossom, whose fragile efflorescence so captivates attention during the bloom of spring. Crucially, appreciation of its beauty may be heightened by one's awareness of its transiency, in a way that would be missing if its florets were a permanent feature of the landscape. Similarly, people's delight at the innocence of childhood partly derives from a sorrowful understanding that this phase passes all too quickly; conversely, there would be something sinister about a person forever stuck in juvenescence. Thus, as 
Prusinski (2013, p. 23) puts it, "The beauty lies not in the object itself, but in the whole experience, transformation, and span of time in which the object is present and changing."

The sensibility captured by the term mono no aware came to prominence during the Tokugawa period (1603-1868), when it was suggested that this sensitivity, this "capacity to understand the world directly, immediately, and sympathetically" was a distinguishing feature of the Japanese character (Woolfolk, 2002, p. 23). We arguably see a similar phenomenon in the West during the Romantic period, as in the works of Goethe, when melancholia was upheld as a sign of a refined soul (Ferber, 2008). However, Zen is less weighed down by the kind of heaviness and even glorification of sadness that characterised romanticism. The mood of mono no aware is more accepting and tranquil, sighing rather than weeping. Given the value of this sensibility, Zen art has sought to capture this spirit of mono no aware, thereby both expressing and inculcating it. The haiku was a particularly effective vehicle for this. (Other art forms also evoked mono no aware, and the other aesthetic moods considered here. However, haiku is the most amenable to presentation in this context.) Matsuo Bashō (1644-1694), arguably the greatest master of the haiku (Hass, 1994), expressed this sense of mono no aware with particular genius, as seen here: "Summer grasses -; the only remains; of warriors' dreams."

Crucially, for our purposes here, mono no aware is not a sensibility that "belongs" to Zen, or to Japanese culture, but is a mode of appreciation that has relevance for all people, and for second wave PP in particular. For instance, cultivating mono no aware might help people to flourish by becoming conscious of the dialectical notion that both positive and negative states are transitory; this could then facilitate a valuable sense of humility and modesty when life is going well, and, conversely, a feeling of hope if life is going badly (Wong, 2012). Similarly, developing an appreciation of mono no aware may help people to accept and even embrace the co-valenced nature of elevated emotions such as love (Lazarus, 2003). As noted above, love is fundamentally dialectical, a potent blend of joy and sadness, safety and fear. As C. S. Lewis (1971, p. 121) put it, "To love at all is to be vulnerable. Love anything and your heart will be wrung and possibly broken." The relevance here of mono no aware is that one's sense of love might be heightened by the realisation that one cannot guarantee its permanence, or secure its presence. We must therefore delight when love does grace us, just as we revel in the fleeting appearance of the cherry blossom. Likewise, if it does pass, one can also try to accept the impermanence of life, and be grateful that one was fortunate to have ever loved at all. These are not necessarily easy sensibilities to cultivate; however, trying to develop mono no aware may nevertheless be a doorway to a "second wave consciousness," i.e., a mode of being that appreciates the dialectical nature of life. In practical terms, there are various ways of encouraging this kind of sensibility. For example, there are therapies that use art to facilitate healing and growth, like poetry therapy (Mazza, 1999). Second wave PP could draw on such practices in developing interventions that engender mono no aware, thereby helping people to develop a greater appreciation of dialectics.

\subsection{Wabi-sabi}

The sense of ephemerality reflected in mono no aware is counterbalanced, in an intriguing way, by the second term, wabi-sabi. Essentially, this captures the strange, desolate beauty of aged or imperfect phenomena. Whereas mono no aware points towards erosion and wear, wabi-sabi reminds us that in this process of changing, a certain desolate beauty is nonetheless retained. Think here of the mysterious power of old ruins, and the reverential qualities of depth and meaning that they can evoke. As Prusinski (2013, p. 25) puts it, wabi-sabi depicts "a crude or often faded beauty that correlates with a dark, desolate sublimity." The aesthetic categories of wabi (rustic beauty) and sabi (aged beauty) can be treated separately, as elucidated below, as each 
bring subtly different qualities to the compound term. Nevertheless, as Park (2005) outlines, these are ultimately complementary concepts that are usually combined to form a coherent aesthetic sense, characterised by awareness, and, indeed, appreciation of (1) austerity, (2) imperfection, and (3) the passage of time. This sense is depicted by Tanizaki (1933, pp. 11-12) in his classic exposition of Zen aesthetics "In Praise of Shadows." He describes preferring a "pensive lustre to a shallow brilliance, a murky light that, whether in a stone or an artefact, bespeaks a sheen of antiquity ... We love things that bear the marks of grime, soot, and weather, and we love the colours and the sheen that call to mind the past that made them." To fully appreciate the nuances of this sensibility, let us examine its components in turn.

With wabi, appreciation of the impermanence of existence is reflected in the idea that we do injustice to life if we only value that which appears perfect and complete. Rather, we should endeavour to see the grace in all seasons, as it were. As the $14^{\text {th }}$ century monk Kenkō asked, "Are we to look at cherry blossoms only in full bloom, at the moon only when it is cloudless? ... Gardens strewn with faded flowers are worthier of our admiration" (cited in Keene, 1967, p. 115). This means not abhorring phenomena for being imperfect, but, rather, valuing their unique gifts. This aesthetic emerges in the art of tea, where flawed utensils are more prized than "perfect" ones; reactions to these items are thus illustrative of a person's understanding of life - as the $17^{\text {th }}$ Century Sen no Rikyū put it, "There are those who dislike a piece when it is even slightly damaged; such an attitude shows a complete lack of comprehension" (cited in Hirota, 1995, p. 226). Thus, wabi reflects a deep acceptance of life and its imperfections, in contrast to the futile quest to create perfect conditions. This has obvious relevance to PP, as discussed further below. As Hirota puts it, "Wabi means that even in straitened circumstances no thought of hardship arises. Even amid insufficiency, one is moved by no feeling of want ... If you complain that things have been ill-disposed - this is not wabi."

Similarly, sabi captures the profundity and mysterious elegance of aged or ancient phenomena, the rustic/rusty patina that lends these gravitas and significance. Even as things change and age (as per mono no aware), there is beauty in this very process. Sabi thus distils the notion of aging well, in the sense of "ripe with experience and insight," together with the evocative feelings of "tranquillity, aloneness" and "deep solitude" that accompany the passage of time (Hammitzsch, 1979, p. 46). A haiku by Bashō captures the lonely beauty of sabi: "Solitary now -; Standing amidst the blossoms; Is a cypress tree" (cited in Dyrness \& kärkkäinen, 2008, p. 66). As with wabi, this sensibility has relevance for second wave PP, since our sorrow the passage of time, for instance, might be transmuted if we could see it through such eyes. Indeed, Zen art aims at just this kind of "re-evaluation" of beauty, finding value in what was previously judged to lack it (Cooper, 2013). For instance, Zen paintings often seek to capture the dignity of aged phenomena, like the bleak power of a withered tree in winter. Or again, Hammitzsch (1979) describes how the tea ceremony is designed to induce a sense of sabi (among other qualities), e.g., in the way it is ideally taken in a secluded, time-worn tea house, with aged, antique utensils. (As a reflective note, this last sentence was difficult to compose, due to a dearth of English words pertaining to aging that have a positive connotation, which arguably reflects a relative lack of the sabi aesthetic in Western culture.) As Prusinski (2013, p. 32) explains, these elements strengthen "one's consciousness of space and time" - including the relative impermanence and unimportance of the tea-taking participants themselves - thereby creating a "heightened spirituality."

As with mono no aware, this wabi-sabi sensibility has relevance for second wave PP. For instance, one of the dialectical insights of second wave PP is the paradoxical notion that it is the effort to seek happiness that creates the very dissatisfaction one aims to alleviate; it is the act of 
resisting what is, and seeking a "better" state of affairs, that stimulates the feeling of unhappiness. This insight has been recognised in diverse contexts, from Buddhism (Watts, 1957) to stoicism (McMahon, 2006) to contemporary self-regulation coping theory (Carver \& Scheier, 1990), and has, furthermore, been corroborated in empirical research (Mauss, Tamir, Anderson, \& Savino, 2011). What is thus striking about wabi-sabi is that it offers us the opportunity to reevaluate our circumstances, to reappraise them as having value, as opposed to being deficient. For example, values promulgated by Western capitalism might lead one to valorise new or perfect objects, and likewise to regard worn or imperfect ones as dissatisfactory. In this conventional mode of thinking, one might thus be discontent with old possessions, and not only covet new items, but come to believe that happiness consists in the acquisition of these. And, as scholars such as Kasser (2011) have shown, this kind of materialism is detrimental to people's own wellbeing, as well as to the environment. As such, the value of this aesthetic mode is not limited to personal happiness, but could have wider implications, such as addressing the acquisitive materialism that is exacerbating our current environmental crisis (Cooper, 2013).

Essentially, in cultivating a wabi-sabi sensibility, one might learn to re-evaluate beauty, and, indeed, even reappraise happiness itself, so that one not only accepts the imperfections of existence, but even sees the subtle beauty in these very "flaws" (which would then be no longer perceived as flaws). For instance, Zen Buddhism has developed a beautiful approach to ceramics, known as kintsugi, which epitomises this principle of wabi-sabi. Broken pieces are repaired using a precious gold lacquer ( $k i n$ means golden, and tsugi means joinery). Thus, the fault lines are not hidden or regarded as blemishes, but rather are accentuated and made beautiful. This metaphor may also be of value to PP. For instance, scholars working on the concept of posttraumatic growth often deploy a metaphor of a broken/shattered vase to describe the phenomenon, whereby the trauma survivor is encouraged to view their recovery as akin to refashioning the pieces of the vase into a meaningful configuration (Joseph, 2012). Clearly, notions like kintsugi have the potential to bring additional depth and significance to the vase metaphor, and thus to the healing process, helping people to find value, meaning, and even beauty in their scars and vulnerabilities.

\subsection{Yügen}

Finally then, is yūgen, translated by Parkes (2011) as "profound grace," and described as the most "ineffable" of aesthetic concepts. In philosophical texts it means "dark" or "mysterious," and alludes to the unfathomable depths of existence, and the fundamental inability of the mind to comprehend these depths. As Suzuki (1959, pp. 220-221) elucidates, yūgen is "a compound word, each part, $y \bar{u}$ and gen, meaning 'cloudy impenetrability,' and the combination meaning 'obscurity,' 'unknowability,' 'mystery,' 'beyond intellectual calculability,' but not 'utter darkness." Similarly, Kaula (1960, pp. 69-70) describes it as the "sense of the mysterious quiescence beneath all things." Thus, yūgen reflects the notion that the mystery of existence may be ineffable and elusive, and beyond rational understanding, but nevertheless can be sensed in some inchoate, intuitive way (Tsubaki, 1971). As Suzuki continues, "It is hidden behind the clouds, but not entirely out of sight, for we feel its presence, its secret message being transmitted through the darkness however impenetrable to the intellect." Moreover, yügen does not simply reflect one's awareness of these mysterious depths, but the way one might also be moved in the core of one's being by these mysteries, without quite knowing why. Kamo no Chōmei (1212) characterises yügen thus: "It is like an autumn evening under a colorless expanse of silent sky. Somehow, as if for some reason that we should be able to recall, tears well uncontrollably" (cited in Dyrness \& kärkkäinen, 2008, p. 65). 
As with mono no aware and wabi-sabi, Zen art endeavours to capture this elusive sense of yügen. Moreover, as with these other aesthetic moods, art is particularly effective at conveying it, at least compared to discursive modes of representation (which are intrinsically unsuited to representing the ineffable). As Kaula (1960, pp. 69-70) explains, the sense that such art attempts to evoke is a "muted, tranquil world in which nothing remains immutably fixed, a world of mist, rain, and wind, of snow and withering flowers." The quiescent depths of such a world are "too fragile and elusive ... to be rationally understood or deliberately controlled," but can nevertheless be alluded to by the skilful artist and perceived by the sensitive observer. However, Zen does not tend to convey this sensibility through ostensibly incomprehensible works of art, as, for example, found in post-modern Western "abstract" art. Rather, Zen art depicts "ordinary" natural phenomena, doing so as an example of the "direct pointing" to the ultimate nature of reality that Zen in general aims towards. Just as the Zen practitioner's "Buddha nature" is demonstrated by seemingly prosaic acts such as eating or walking, Zen artists use natural phenomena to evoke this sense of yügen. For instance, the following seminal haiku, by Basho, is often regarded as the ultimate expression of yügen in Japanese poetry (Watts, 1957): "On a withered branch; A crow is perched; In the autumn evening."

As with the other aesthetic principles, yügen is (or rather, could be) of great value to second wave PP. Arguably, Western psychology has already identified states of experience that are similar to yūgen, the kind of profound, transcendental states described by Maslow (1972) as "peak experiences" or by Wong (2009b) as chaironic happiness. Deeply profound and moving, such moments go far beyond mere hedonic pleasure or even eudaimonic meaning, but shake the very core of one's being, engendering life-changing experiences of self-transcendence (Wong, 2016b). Here one surpasses all concepts, entering the realm of awe, in which one is rendered speechless, powerless and even terrified by the mysterious power and grace of the universe (Keltner \& Haidt, 2003). There are parallels here with Frankl's (1963) notion of the search for "ultimate" meaning, which is beyond human comprehension (Wong, 2009c). However, what is unusual and potent about yügen is the apparently "ordinary" nature of the phenomena that can evoke it, as reflected in Basho's haiku. Western conceptions of peak experience tend to imply that these can only be experienced on some literal or metaphorical (e.g., developmental) mountain peak. With yūgen, though, there is the profound experience of the ordinary - which is within everyone's reach being revealed as extraordinary, as if lifting a veil on the sacred. And, as such, this is perhaps the place to end: in appreciating the dialectics of flourishing, as second wave PP aims to do, the fundamental point is the value of transcending narrow human constructs and categories, and glimpsing the strange, mysterious beauty of life.

\section{Conclusion}

This paper has suggested that PP might benefit from engaging with Zen aesthetic principles. It was argued that second wave PP is characterised by an awareness of the dialectical nature of flourishing, and of the way wellbeing involves a delicate blend of apparently positive and negative elements. Historically, this kind of dialectical appreciation has been developed by Eastern philosophies, particularly Zen, hence the rationale for suggesting that PP could learn from Zen. Indeed, research has already shown that PP can benefit from engaging with Zen aesthetics, which can help illustrate the dialectical nature of flourishing (Wong, 2012). As such, to facilitate an awareness of Zen aesthetics in PP, this paper outlined three Zen aesthetic principles - mono no aware (pathos of life), wabi-sabi (desolate beauty), and yūgen (profound grace) - showing in each case how PP could benefit from engendering these sensibilities. Moreover, Zen aesthetics also suggests new directions for PP, particularly research into the possibility of 
attaining inner contentment - even amidst difficult life circumstances - through selfdevelopment and cultivation. This paper has merely scratched the surface of what Zen aesthetics - and Eastern philosophy more broadly - can potentially offer PP as it matures and evolves as a discipline. Future work will therefore be needed to allow the field to truly harness the insights of these immense traditions.

\section{Authors}

Tim Lomas

University of East London

t.lomas@uel.ac.uk

\section{Publishing Timeline}

Received 28 December 2015

Accepted 9 July 2016

Published 14 September 2016

\section{References}

Ahmed, S. (2010). The promise of happiness. New York, NY: Duke University Press. http://dx.doi.org/10.1215/9780822392781

Bai, H. (2002). Zen and the art of intrinsic perception: A case of haiku. Canadian Review of Art Education, $28(1), 1-24$.

Barnett, R. J. (1986). Taoism and biological science. Zygon, 21(3), 297-317. http://dx.doi.org/10.1111/j.14679744.1986.tb00751.x

Bauman, Z. (2013). Liquid love: On the frailty of human bonds. New York, NY: John Wiley \& Sons.

Brady, E. (2013). The sublime in modern philosophy: Aesthetics, ethics, and nature. Cambridge, England: Cambridge University Press. http://dx.doi.org/10.1017/CBO9781139018098

Bryant, B. (2003). The wheel of time sand mandala: Visual scripture of Tibetan Buddhism. Boston, MA: Snow Lion.

Burton, D. (2001). Is Madhyamaka Buddhism really the middle way? Emptiness and the problem of nihilism. Contemporary Buddhism, 2(2), 177-190. http://dx.doi.org/10.1080/14639940108573749

Carver, C. S., \& Scheier, M. F. (1990). Origins and functions of positive and negative affect: A controlprocess view. Psychological Review, 97(1), 19-35. http://dx.doi.org/10.1037/0033-295X.97.1.19

Chōmei, K. n. (1212/1968). An account of my hut (N. Soseki, Trans.). In D. Keene (Ed.), Anthology of Japanese literature. New York, NY: Grove Press.

Chung-yuan, C. (1977). Tao: A new way of thinking. A translation of the Tao Te Ching, with introduction and commentaries. New York, NY: Harper and Row.

Coningham, R., Acharya, K., Strickland, K., Davis, C., Manuel, M., Simpson, I., . . Sanderson, D. (2013). The earliest Buddhist shrine: Excavating the birthplace of the Buddha, Lumbini (Nepal). Antiquity, 87(338), 1104-1123. http://dx.doi.org/10.1017/S0003598X00049899

Cooper, T. M. (2013). The wabi sabi way: Antidote for a dualistic culture? Journal of Conscious Evolution, 10. http://cejournal.org/issue-10-2013

Cunningham, S. B. (1999). Getting it right: Aristotle's "Golden Mean" as Theory Deterioration. Journal of Mass Media Ethics, 14(1), 5-15. http://dx.doi.org/10.1207/S15327728JM140101

Davidson, R. M. (2003). Indian esoteric Buddhism: Social history of the tantric movement. Delhi, India: Motilal Banarsidass.

Dyrness, W. A., \& kärkkäinen, V.-M. (2008). Global dictionary of theology. Nottingham, England: IVP Academic.

Fang, T. (2012). Yin yang: A new perspective on culture. Management and Organization Review, 8(1), 25-50. http://dx.doi.org/10.1111/j.1740-8784.2011.00221.x

Ferber, M. (2008). A companion to European romanticism. London, England: John Wiley \& Sons. 
Frankl, V. E. (1963). Man's search for meaning: An introduction to logotherapy. New York, NY: Washington Square Press.

Fung, L.-Y. (1948). A short history of Chinese philosophy. New York, NY: The Free Press.

Gombrich, R. F. (2006). How Buddhism began: The conditioned genesis of the early teachings. London, England: Routledge.

Hammitzsch, H. (1979). Zen in the art of the tea ceremony (P. Lemesurier, Trans.). New York, NY: Arkana.

Hass, R. (Ed.). (1994). The essential haiku: Versions of Basho, Buson, and Issa. London, England: Ecco.

Held, B. S. (2004). The negative side of positive psychology. Journal of Humanistic Psychology, 44(1), 9-46. http://dx.doi.org/10.1177/0022167803259645

Hermann, E. J. (1990). The near-death experience and the Taoism of Chuang Tzu. Journal of Near-Death Studies, 8(3), 175-190. http://dx.doi.org/10.1007/BF01074002

Hirota, D. (Ed.). (1995). Wind in the pines: Classic writings of the way of tea as a Buddhist path. Fremont, CA: Asian Humanities Press.

Hisamatsu, S. (1971). Zen and the fine arts (G. Tokiwa, Trans.). New York, NY: Kodansha International.

Ho, D. Y. (1995). Selfhood and identity in Confucianism, Taoism, Buddhism, and Hinduism: Contrasts with the West. Journal for the Theory of Social Behaviour, 25(2), 115-139. http://dx.doi.org/10.1111/j.14685914.1995.tb00269.x

Ivtzan, I., Lomas, T., Hefferon, K., \& Worth, P. (2015). Second wave positive psychology: Embracing the dark side of life. London, England: Routledge.

Ji, L. J., Nisbett, R. E., \& Su, Y. (2001). Culture, change, and prediction. Psychological Science, 12(6), 450456. http://dx.doi.org/10.1111/1467-9280.00384

Joseph, S. (2012). What doesn't kill us: The new psychology of posttraumatic growth. London, England: Piatkus Little Brown.

Kasser, T. (2011). Ecological challenges, materialistic values, and social change. In R. Biswas-Diener (Ed.), Positive Psychology as Social Change (pp. 89-108). New York, NY: Springer. http://dx.doi.org/10.1007/978-90-481-9938-9 6

Kaula, D. (1960, September). On Noh drama. The Tulane Drama Review, 69-70. http://dx.doi.org/10.2307/1124903

Keene, D. (1967). Essays in idleness: The Tsurezuregusa of Kenkō. New York, NY: Columbia University Press.

Keltner, D., \& Haidt, J. (2003). Approaching awe, a moral, spiritual, and aesthetic emotion. Cognition $\mathcal{E}$ Emotion, 17(2), 297-314. http://dx.doi.org/10.1080/02699930302297

King, L. A. (2001). The hard road to the good life: The happy, mature person. Journal of Humanistic Psychology, 41(1), 51-72. http://dx.doi.org/10.1177/0022167801411005

King, R. (1999). Orientalism and the modern myth of "Hinduism". Numen, 46(2), 146-185. http://dx.doi.org/10.1163/1568527991517950

Kirkland, R. (2004). Taoism: The enduring tradition. London, England: Routledge.

Lazarus, R. S. (2003). Does the positive psychology movement have legs? Psychological Inquiry, 14(2), 93109.

Lewis, C. S. (1971). The four loves. New York, NY: Houghton Mifflin Harcourt.

Linley, P. A., \& Joseph, S. (2004). Applied positive psychology: A new perspective for professional practice. In P. A. Linley \& S. Joseph (Eds.), Positive psychology in practice (pp. 3-12). Hoboken, NJ: John Wiley \& Sons. http://dx.doi.org/10.1002/9780470939338.ch1

Lomas, T. (2015). Positive cross-cultural psychology: Exploring similarity and difference in constructions and experiences of wellbeing. International Journal of Wellbeing, 5(4), 60-77.

http://dx.doi.org/10.5502/ijw.v5i4.3

Lomas, T. (2016a). A meditation on boredom: Re-appraising its value through introspective phenomenology. Qualitative Research in Psychology. Advance online publication. http://dx.doi.org/10.1080/14780887.2016.1205695

Lomas, T. (2016b). Positive art: Artistic expression and appreciation as an exemplary vehicle for flourishing. Review of General Psychology, 20(2), 171-182. http://dx.doi.org/10.1037/gpr0000073 
Lomas, T. (2016c). Recontextualising mindfulness: Theravada Buddhist perspectives on the ethical and spiritual dimensions of awareness. Psychology of Religion and Spirituality. Advance online publication. http://dx.doi.org/10.1037/rel0000080

Lomas, T. (2016d). Towards a positive cross-cultural lexicography: Enriching our emotional landscape through 216 'untranslatable' words pertaining to wellbeing. The Journal of Positive Psychology, 11(5), 546-558. http://dx.doi.org/10.1080/17439760.2015.1127993

Lomas, T., \& Ivtzan, I. (2015). Second wave positive psychology: Exploring the positive-negative dialectics of wellbeing. Journal of Happiness Studies. Advance online publication. http://dx.doi.org/10.1007/s10902-015-9668-y

Maslow, A. H. (1972). The farther reaches of human nature. London, England: Maurice Bassett.

Mauss, I. B., Tamir, M., Anderson, C. L., \& Savino, N. S. (2011). Can seeking happiness make people unhappy? Paradoxical effects of valuing happiness. Emotion-APA, 11(4), 807-815. http://dx.doi.org/10.1037/a0022010

Mazza, N. (1999). Poetry therapy: Interface of the arts and psychology: Boca Raton, FL: CRC Press.

McMahon, D. M. (2006). Happiness: A history. New York, NY: Atlantic Monthly Press.

McNulty, J. K., \& Fincham, F. D. (2011). Beyond positive psychology? Toward a contextual view of psychological processes and well-being. American Psychologist, 67(2), 101-110.

http://dx.doi.org/10.1037/a0024572

Merriam-Webster. (2014). Dialectic. http://www.merriam-webster.com/dictionary/dialectic

Nhat Hanh, T. (2000). The path of emancipation. Berkeley, CA: Parallax Press.

Norem, J. K., \& Cantor, N. (1986). Defensive pessimism: Harnessing anxiety as motivation. Journal of Personality and Social Psychology, 51(6), 1208-1217. http://dx.doi.org/10.1037/0022-3514.51.6.1208

Oldstone-Moore, J. (2003). Taoism: Origins, beliefs, practices, holy texts, sacred places. Oxford, England: Oxford University Press.

Parkes, G. (2011). Japanese aesthetics. Stanford encyclopedia of philosophy. http://plato.stanford.edu/entries/japanese-aesthetics/

Pawelski, J. O. (2016a). Defining the 'positive' in positive psychology: Part I. A descriptive analysis. The Journal of Positive Psychology, 11(4), 339-356. http://dx.doi.org/10.1080/17439760.2015.1137627

Pawelski, J. O. (2016b). Defining the 'positive' in positive psychology: Part II. A normative analysis. The Journal of Positive Psychology, 11(4), 357-365. http://dx.doi.org/10.1080/17439760.2015.1137628

Prusinski, L. (2013). Wabi-sabi, mono no aware, and ma: Tracing traditional Japanese aesthetics through Japanese history. Studies on Asia, 2(1), 21-45.

Ryff, C. D., \& Singer, B. (2003). Ironies of the human condition. Well-being and health on the way to mortality. In L. G. Aspinwall \& U. M. Staudinger (Eds.), A psychology of human strengths (pp. 271-287). Washington, DC: American Psychological Association. http://dx.doi.org/10.1037/10566-019

Saito, Y. (2005). The Japanese Aesthetics of Imperfection and Insufficiency. The Journal of Aesthetics and Art Criticism, 55(4), 377-385. http://dx.doi.org/10.2307/430925

Sameroff, A. (2010). A unified theory of development: A dialectic integration of nature and nurture. Child Development, 81(1), 6-22. http://dx.doi.org/10.1111/j.1467-8624.2009.01378.x

Schimmack, U., Oishi, S., \& Diener, E. (2002). Cultural influences on the relation between pleasant emotions and unpleasant emotions: Asian dialectic philosophies or individualism-collectivism? Cognition \& Emotion, 16(6), 705-719. http://dx.doi.org/10.1080/02699930143000590

Schwartz, B. (2000). Self-determination: The tyranny of freedom. American Psychologist, 55(1), 79-88. http://dx.doi.org/10.1037/0003-066X.55.1.79

Seligman, M. E. P. (1990). Learned optimism. New York, NY: Pocket Books.

Smith, H. (1972). Tao now: An ecological testament. In I. G. Barbour (Ed.), Earth might be fair (pp. 62-81).

Englewood Cliffs, NJ: Prentice-Hall.

Suzuki, D. T. (1959/1973). Zen and Japanese culture. Princeton, NY: Princeton University Press.

Suzuki, D. T. (1961). Essays in Zen Buddhism. New York, NY: Grove Press.

Tanizaki, J. (1933/2001). In praise of shadows. New York, NY: Random House.

Thrangu, K. (1993). The practice of tranquility and insight: A guide to Tibetan Buddhist meditation (R. Roberts, Trans.). Boston, MA: Shambhala. 
Tsubaki, A. T. (1971). Zeami and the transition of the concept of yūgen: A note on Japanese aesthetics. Journal of Aesthetics and Art Criticism, 30(1), 55-67. http://dx.doi.org/10.2307/429574

Tzu, L. (1963). Tao Te Ching (D. C. Lau, Trans.). New York, NY: Viking Penguin.

Watts, A. W. (1957). The way of Zen. London, England: Penguin Books.

Wilhelm, H. (1950/1977). The I Ching or book of changes (C. F. Baynes, Trans.). New York, NY: Princeton University Press.

Williams, P. (2008). Mahayana Buddhism: The doctrinal foundations. London, England: Routledge.

Wong, P. T. P. (2009a). Chinese positive psychology. In S. Lopez (Ed.), Encyclopedia of positive psychology (Vol. 1, pp. 148-156). Oxford, England: Wiley Blackwell.

Wong, P. T. P. (2009b). Positive existential psychology. In S. Lopez (Ed.), Encyclopedia of positive psychology (Vol. 1, pp. 345-351). Oxford, England: Wiley Blackwell.

Wong, P. T. P. (2009c). Viktor Frankl: Prophet of hope for the 21st century. In A. Batthyany \& J. Levinson (Eds.), Existential psychotherapy of meaning: Handbook of logotherapy and existential analysis. Phoenix, AZ: Zeig, Tucker \& Theisen.

Wong, P. T. P. (2011). Positive psychology 2.0: Towards a balanced interactive model of the good life. Canadian Psychology/Psychologie Canadienne, 52(2), 69-81. http://dx.doi.org/10.1037/a0022511

Wong, P. T. P. (2012). The adaptive benefits of acceptance: Keynote address. Paper presented at the 3rd Australian Conference of Positive Psychology and Wellbeing, Wollongong, Australia.

Wong, P. T. P. (2016a). Chinese positive psychology revisited. International Journal of Existential Psychology \& Psychotherapy, 6(1). http://www.drpaulwong.com/ijepp-1-6/

Wong, P. T. P. (2016b). Meaning-seeking, self-transcendence, and well-being. In A. Batthyany (Ed.), Logotherapy and existential analysis (Vol. 1, pp. 311-322). Vienna: Proceedings of the Viktor Frankl Institute. http://dx.doi.org/10.1007/978-3-319-29424-7 27

Woolfolk, R. L. (2002). The power of negative thinking: Truth, melancholia, and the tragic sense of life. Journal of Theoretical and Philosophical Psychology, 22(1), 19-27. http://dx.doi.org/10.1037/h0091192 